\title{
Primary Ovarian Failure
}

National Cancer Institute

\section{Source}

National Cancer Institute. Primary Ovarian Failure. NCI Thesaurus. Code C113352.

Absent or premature cessation of ovarian function due to a pathologic process

originating within the ovaries. 